Please do not remove this page

RMIT

UNIVERSITY

\title{
Sustainability assessment of supply chains with engineering services focus
}

Mo, John

https://researchrepository.rmit.edu.au/esploro/outputs/9921859130601341/filesAndLinks?institution=61RMIT_INST\&index=null

Mo, J. (2012). Sustainability assessment of supply chains with engineering services focus. International Journal of Enterprise Network Management, 5(1), 72-91. https://doi.org/10.1504/IJENM.2012.045596 Document Version: Submitted Version

Published Version: https://doi.org/10.1504/IJENM.2012.045596

Repository homepage: https://researchrepository.rmit.edu.au

(C) 2012 Inderscience Enterprises Ltd

Downloaded On 2023/04/26 18:36:08 +1000

Please do not remove this page 
Thank you for downloading this document from the RMIT Research Repository.

The RMIT Research Repository is an open access database showcasing the research outputs of RMIT University researchers.

RMIT Research Repository: http://researchbank.rmit.edu.au/

\section{Citation:}

Mo, J 2012, 'Sustainability assessment of supply chains with engineering services focus ', International Journal of Enterprise Network Management, vol. 5, no. 1, pp. 72-91.

See this record in the RMIT Research Repository at:

http://researchbank.rmit.edu.au/view/rmit:17981

Version: Submitted Version

Copyright Statement: (c) 2012 Inderscience Enterprises Ltd

Link to Published Version:

http://dx.doi.org/10.1504/IJENM.2012.045596 


\title{
Sustainability assessment of supply chains with engineering services focus
}

\begin{abstract}
The use of information and communication technologies to support inter-company collaboration in the form of virtual enterprise is a critical factor to the success of the venture. Due to the dynamic nature of the business partnership, the provision of communication infrastructure among the partners needs to be interoperable and fit for the purpose. This paper uses the case study research methodology to study the e-collaboration patterns of five cases in which the companies have particular focus on providing knowledge intensive engineering services to customers. The supply chains have a vibrant nature in their structure and are modelled as virtual enterprises that have their own phases of development. Depending on the communication capabilities, individual partners in the virtual enterprise may have to invest heavily in order that they can participate in large scale projects. Companies without a competent communication technology profile need to consider what capability they should acquire and when that capability will be useful. The study concluded that a 5-level communication framework can be used to assess the sustainability of the virtual enterprise and assist supply chain partners to consider whether they would invest to attain the acceptable level of competency to join.
\end{abstract}

\section{Keywords}

Virtual enterprise, Engineering services supply chains, Sustainability indicator, Sustainability assessment, Communication technology level, Virtual Enterprise life cycle

\section{Introduction}

Small and medium enterprises (SMEs) form an important constituent of any modern economy. According to the Council of Small Business Organisations of Australia, there are more than 1.88 million small businesses in Australia employing 3.6 million people and with a total capitalised worth of $\$ 4.3$ trillion, 4 times that of the Australian stock exchange (COSBOA, 2011). However, SMEs are subject to severe competition from global suppliers. This problem is particularly obvious in labour intensive industry sectors such as textile, apparel and furniture manufacturing. To circumvent this trend, many SMEs are specialising in customisable products which offer higher value. Efforts to assist individual sectors to become more competitive meet with varying successes (Mo et al, 2001; Beaumont, 1998; Ekanem, 2005). These efforts have introduced changes in manufacturing industry in developed countries forcing companies to work together in different forms of collaborative supply chains (Nemes \& Mo, 2004). One of the forms is known as Virtual Enterprise (VE) which is characterised by low volume, project based, niche high value engineering work (Van den Berg \& Tolle, 2000; Beckett, 2003). Interactions at organizational, technical, social and commercial levels give rise to properties that have to be dealt with carefully (Pinsonneault \& Caya, 2005; Zarour et al, 2005). On the other hand, this type of supply chains are flexible, dynamic with minimal or sometimes no contractual agreements among the partners, and can be created and disbanded in very short time frames (Hao et al, 2005);.

The high agility in these virtual engineering enterprises give rise to a number of issues:

- Engineering services are one-off development and very dependent on the human relationships between people. The work (services) can vary significantly between 
contracts. Design of the system supporting this type of agile business is necessary to reduce project risks (Lockett et al, 2011).

- Mismatch of organisational culture and miscommunication give rise to a lot of hiccups due to the lack of formal processes and procedures. These are involved and must be agreed to by partners. Small problems exist in many activities causing significant delays and impose high risks to the service providers (Braziotis \& Tannock, 2007).

- It is important that companies in the VE have access to an effective infrastructure so that they can work together efficiently to ensure profitability and sustainability of the business (Cheng \& Popov, 2004).

A virtual enterprise offering engineering services comprises people and technologies that adaptively compute and adjust a system's changing value of knowledge (Spohrer et al, 2007). Abe (2005) described a service-oriented solution framework designed for Internet banking. The Institute of Manufacturing at University of Cambridge summarised the nature of services systems as "dynamic configurations of people, technologies, organisations and shared information that create and deliver value to customers, providers and other stakeholders" (IfM and IBM, 2008).

These studies show that a clearly defined enterprise infrastructure linking different parts of the service supply chain has to be created and managed for supporting complex services. The question is how this enterprise infrastructure can be defined properly to reduce the risk of system design error. Unfortunately, this type of study must be done in situ, as evidence from the some of the earlier engineering service system design projects (Shinonome et al, 1997; Mo et al, 1998). This paper describes a case study research approach investigating the enterprise infrastructure of service supply chains in several industries. The methodology is adopted from Yin (2009) and has particular focus on the contemporary nature of the information and communication technologies (ICT) available at particular time in the studies.

\section{Case study research design}

Case study research methodology has been used extensively in a number of disciplines including accounting, management, education and medical profession (Scapens, 2011; Perry, 1998; Hansen, 2011). Case study research is particularly useful in identifying specific characteristics that affect system performances. Serra and Ferriera (2010) identified four strategy pillars in five case studies of well-known multinational corporations. In supply chain case study research, Seuring (2008) surveyed 68 papers supply chain sustainabililty and supply chain performance and concluded that more data should be collected from supply chains and that the research process should be more comprehensively documented and reviewed. Lewis et al (2011) research three cases studies in the energy and maintenance management practices area. They found that there was an interdependent link between energy and maintenance management; reactive maintenance and it should be better understood when the teams worked together for service solutions.

However, participation in a supply chain is not a trivial exercise for companies. It involves substantial investments and balancing effort both in terms of capital as well as staff commitments. For example, in a performance oriented service system, improvement of service level quality can be achieved by increasing inventory cost (Shen and Daskin, 2005). Van Donk et al (2011) carried out a structured literature review on the influence of ICT in supply chain management. They found that despite inconsistency in reported findings in this field of research, there were general positive performance outcomes of supply chains due to ICT system development. Kucza and Gebauer (2011) investigated the forms of servitization 
of products could help global manufacturing firms to develop new service-based and relationship-based value propositions for customers. Four such forms were identified: integrated and ethnocentric; integrated and polycentric; separated and polycentric; and separated and geocentric.

Bhaskaran and Gligorovska (2009) surveyed the reasons why SMEs in the food industry in Australia adopted or refused ICT in their organizations. For those SMEs that adopted ICT, they investigated their prioritization in adopting ICT capabilities. They found that the majority of SMEs only adopted e-mail and informational websites and refused to use extranets, e-business, e-commerce and other more sophisticated capabilities. There were significant scale-up issues when laddering-up to more advanced technologies.

Bielli and Bielli (2008) presented a conceptual model of a SMEs network in the European project CO-DESNET. The coordination of distributed and autonomous agents characteristics of the collaborative enterprise clusters were represented by suitable models such that global performances could be evaluated. The model was validated by a case study outlining a transition to the Net Economy of SMEs in Italy. Research to develop a general theory of service with well-defined questions, tools, methods and practical implications for society has been reported by Johannson and Olhager (2006). They examined the linkage between goods manufacturing and service operations and developed a framework for process choice in joint manufacturing and after-sales service operations. It is generally accepted that an important element in the design of service systems is the architecture of the system itself.

Unfortunately, the impact of adapting to a service supply chain is very high for SMEs. An essential element in the design of a service enterprise is to develop efficient system architecture and provide the right resources to the right service tasks. By synchronising organisational activities, sharing information and reciprocating one another's technologies and tools, each partner in the service enterprise will be able to provide services that would have been impossible by individual effort. Hence, this case study research will focus on the supply chains with particular emphasis on engineering work that requires the use of ICT in the provision of support services to customers.

One of the most difficult issues in the case study research is the definition of unit of analysis. Grünbaum (2007) provided a useful elaboration of the concept by examples of generic case studies based on modifications of Yin's (2004) case study design. Huang (2008) interviewed top management of 40 SMEs in Taiwan on their perceptions of IT components in business and found five internal strategic factors inhibiting top management support in IT adoption. Holschbach and Hofmann (2011) used case study evidence from eight manufacturing and eight service companies. They found that companies did not use quality management for externally sourced business services to its full potential. There were major risks associated with quality failures, standardization and quantity of service on the services provided.

Yun et al (2010) investigated construction consulting firms in South Korea and proposed four types of the knowledge mapping models according to the characteristics and conditions of their own construction personnel, construction processes, and knowledge transfer technologies. This helped the companies to develop appropriate knowledge management systems more effectively. Sharma (2007) found that SMEs in India were able to produce internationally acceptable quality goods and services but were unable to secure exposure and economic returns due to the lack of proper information system architecture. Unfortunately, the middle operators, namely, the mediators and brokers used this lack of capabilities in SMEs to obtain undue economic benefits. Hence, it is logical to focus the investigation to companies that are or have the potential of participating in service supply chains and have the need to assess their ICT investment requirements. 


\section{The Virtual Enterprise Reference Architecture}

Virtual enterprises are loosely coupled supply chains with one or a couple of leading companies and a much larger number of SMEs supporting specialised development in the VE. In order to enable the ability to assess the risks of ICT infrastructure development (i.e. the "how to define" question), this paper proposes that if an assessment scheme to assess sustainability of these supply chains is available, companies are able to make decision on whether it is worthwhile to invest in participation. With this capability, SMEs are able to reduce risks of investing unnecessarily in expensive ICT which may not eventually bring profit to the company. However, the research question then becomes "what form of enterprise architecture design this assessment scheme should be based?"

Espinosa and Porter (2011) explored the Viable Systems Model that supported an organizational transformation of sustainability in community and the Complex Adaptive Systems that intended to green two firms in the supermarket industry. Both models were found successful in assisting the stakeholders in the case studies to achieve sustainability. Chiu et al (2007) implemented an e-health multi-agent based system that ensured interoperability and scalable integrated with other systems that the multi-agent system needs to interact. The interoperable architecture of the system using web services, software agents and objects helped to achieve its requirements. Brammer and Walker (2011) surveyed sustainability practices in the public sector in 20 countries. There were significant efforts towards sustainability but the extent varied between countries. These researches indicate that a more structured modelling approach is essential for ascertaining sustainability in service supply chains.

There are two challenges in developing the virtual enterprise system. The first challenge is the difficulty of modelling a supply chain with SMEs. Due to limited staff and resources, the relationships between the functional and performance perspectives in SMEs are difficult to be separated and modelled. For example, Canavesio and Martinez (2007) who tried to model a SME in a supply network required very careful enterprise design to keep it focussed. Dewhurst et al (2002) attempted to "design" the SME architecture but realised the problem with traditional "single perspective" enterprise when modelling SMEs. SMEs tend to take short cuts in work flow and jeopardise continuity and consistency of processes. The difficulty of modelling SMEs not only reduces the ability to improve the efficiency of the supply chain.

The second challenge is the deficiency of existing methodology in dynamic enterprise modelling. Chatha et al (2006) developed a set of context-dependent dynamic models to replicate and analyse historical patterns in order to maintain continuity of manufacturing operations while minimising the impact due to multi-processing within business networks. Yu et al (2000) used multiple views of the enterprise to reuse elements within an enterprise model. However, these modelling approaches can only provide a snapshot of the enterprises at a particular time of the life cycle. As the organisation changes, the staff often lose track of what they need to do and have to create (or recreate) their own processes. Subsequently, the enterprise snapshot does not represent the new enterprise structure and can not be used to plan sustainable performance over an extended period of engineering services time.

One of the well known architecture for VE modelling is the Virtual Enterprise Reference Architecture (VERA) as described by Zwegers et al (2003). It defines the logical, recursive relationships between the Network, the Project and the Product frameworks (Figure 1). 


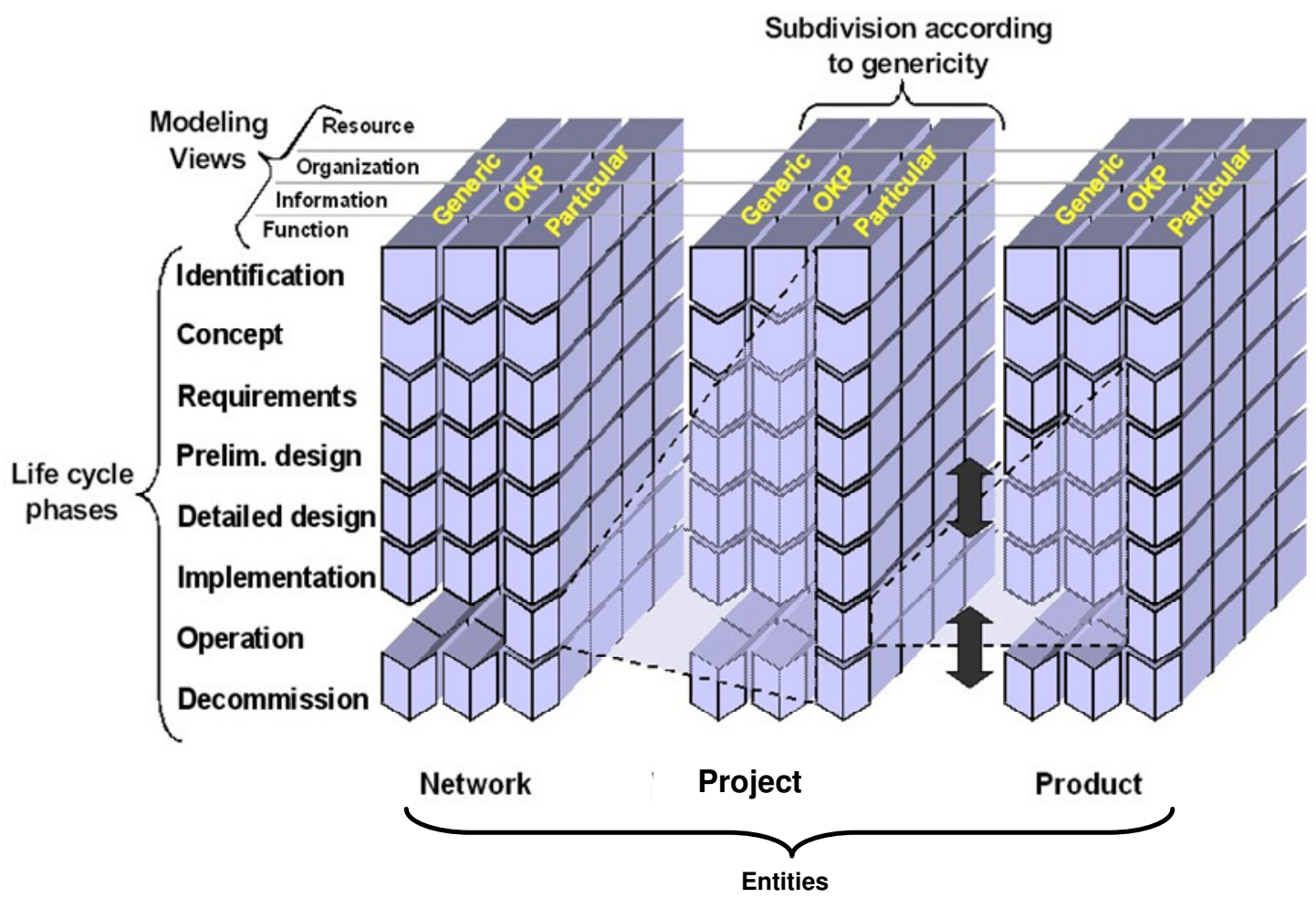

Figure 1 The Virtual Enterprise Reference Architecture

In Figure 1, each of these entities is represented by a life cycle describing the phases from identification to decommission. VERA illustrates that the network can create Projects in its operational phase and, correspondingly, that a Project Entity can create products and/or services in its operational phase.

The life cycle model in VERA was developed from PERA, the Purdue Enterprise Reference Architecture (Williams, 1994). PERA divides the enterprise development process into 3 subsystems: Information Systems, Manufacturing Equipment and Human and Organisational architectures. The interface between Human and Organisational architecture with the other two architectures is known as the "extent of automation". A condition for a virtual enterprise to be successful is a consensus on each of the "extent of automation" affecting information architecture and equipment architecture needs to be agreed among all partners. In essence, the "extent of automation" defines the communication technology level at which the virtual enterprise is to operate.

At different phases of the VERA life cycles, it is natural that the degree of automation will be different. For example, Barradas \& Pinto-Ferreira (2004) studied a tourism virtual enterprise and found that information sharing in the virtual enterprise is highly dependent on the commitment of the members to invest in ICT to some common acceptable levels. However, there is no existing guideline in the VERA evolution process to determine the appropriate level of "automation" for seamless integration. Partners in the VE use a significant amount of time to adjust among themselves towards a commonly acceptable level of automation. The consequence is a lot of confusion and misunderstanding affecting the effectiveness and efficiency of the VE.

In a VE, effective communication is a critical factor in making such a virtual enterprise a success. In the mid 1990s, thick client technology was the favourate technology for communication among distributed design and engineering teams (Mills et al, 1998) but the 
high cost of high speed link prohibited wide spread use of this technology. Alternatively, large scale project execution framework was explored with certain degree of success in a tightly managed project environment (Jiang \& Mo, 2001; Hossam et al, 2002). Nowadays, VE infrastructure using internet based technologies are widely used in business (Malladi \& Min, 2005; Shen et al, 2004; Chattopadhyay \& Mo, 2010).

For communication to be effective, it is necessary that both parties are receptive to the information and messages being transferred. In a computing environment, the international standard Open Systems Interconnection (ISO, 1983) is a framework for communication between computers. An important concept of OSI is its peer-to-peer communication process (Dilts et al, 1991). Hence, two entities cannot communicate unless the lower layer functions are available and operational. Since the primary goal of the VE is to provide engineering services to global customers, it is important to recognise that the focal point of investment decision is on what communication is required for delivery of the service rather than the communication method itself. The VE life cycle phases reflect the work requirement of the VE and hence can be regarded as a pattern indicator of the possibility of continuity in the business. Since sustainability is a combination of business continuity and operational efficiency, modelling the VE using VERA and identifying which life cycle phase the VE is operating will provide an assessment of the sustainability of the supply chain.

\section{The proposition: communication technology levels}

An important feature of a VE is the ability to collaborate through effective communication. A model is required to assist the investment decision process. Nosek (2005) proposed a 3 level collaboration framework for understanding sense making in virtual teams. However, the complexity of communication technology level depends on the task to be carried out at hand. It is necessary to develop a measure of the degree of sustainability of engineering services.

It is proposed that there is a direct relationship between the communication technology level with the maturity of the VE as modelled by VERA. In Figure 1, of the 8 life cycle phases, the identification and decommission phases do not seem to require much communication. The identification phase is ad hoc and often intermittent. In the decommission phase, the supply chain is basically disbanded. As the VE progresses through its life cycle of development to securing real business, everyone in the VE should try to achieve certain level of communication technology in order to participate in the VE effectively. This means certain level of investment must be made in all partners' organisations. For larger organisations, most of the infrastructures have been in place. In many cases, they have the command of the VE on the selection of communication products. SMEs on the other hand, are more passive in participation. Large investment in communication technologies must be considered along with the potential benefits that this investment will bring to them.

To assist companies in deciding how their communication technology level should be developed, we introduce the concept of "communication competency" that indicates how effective the operation of the supply chain is. A five level model is proposed to describe the ICT functionalities required to achieve interoperability across the VE. This model is designated as VE Communication Framework (VCF) in Figure 2. The model adopts the ISO principles that in order for communication to be effective, both sides should have compatible level of ability. 
Partner A

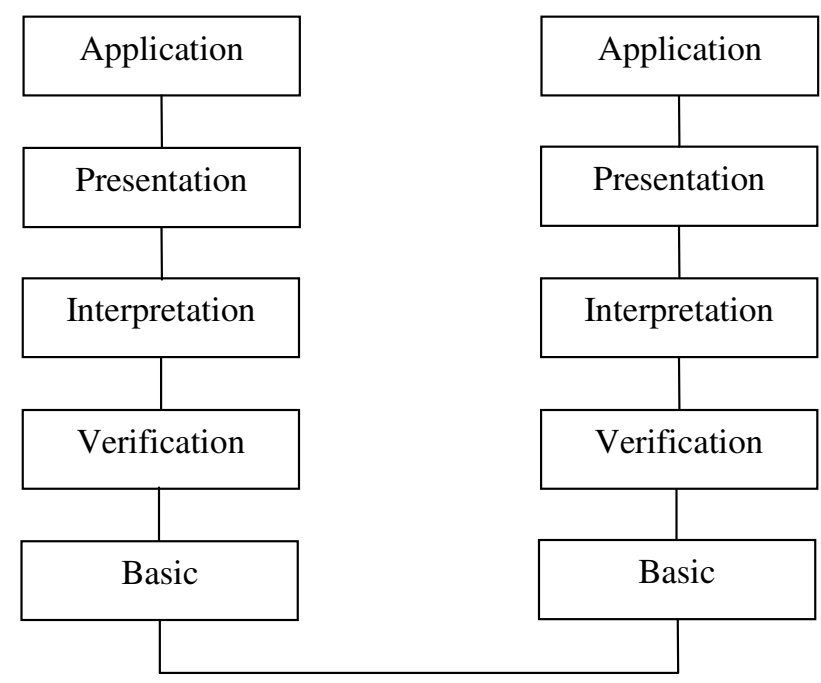

Figure 2 - The VE Communication Framework

\section{Basic level}

The basic level represents the transmission media that will be used in the communication process. The choices depend on the technologies available to the partners in the VE. Functions that are classified in the physical level have the following characteristics:

- Activities are transport in nature. Information is moved physically from one partner (or party) to another.

- There is no change to the form or format of information in the transmission.

Telephone and meetings are typical examples of facilities at this level. This is fundamental to all cases and should exist in order to support any other levels of communication.

\section{Verification level}

The verification level performs the function of collating the information transferred as a unit package and closing the loop between the sender and the receiver. This includes tasks such as receipt certification, content acknowledgement, re-transmit request when errors occur, incomplete delivery handling, master copy filing, etc. In the toolmakers' VE environment, these functions will sometimes be performed by a number of parties, including outsourced entities. Functions that are classified in the verification level have the following characteristics:

- Information for communication is packaged (or unpackaged). Messages that accompany the communication will be coupled with (or decoupled from) the content of the transmission.

- During packaging, the information will be streamlined as required by the communication media at the physical level. Similarly, streamlined information received from the physical level may be re-sequenced to a form that is useful for interpretation.

- Resolving destination information at either side of the level is necessary.

- The content of communication remains unchanged.

Email is the most common form of technology employed at this level. 


\section{Interpretation level}

The interpretation level performs the function of diverting information into relevant streams. It is responsible for interpreting data and ensures collaboration can occur. In a communication process, there are many types of information transmitted. For example, a set of files consisting of some drawings, a project plan and a product specification is received. Each information item will be processed by different people in the company and hence it is necessary to divert parts of this information to different departments for processing. Communication between two communicating parties at this level involves the identification of corresponding functional departments of the partners and gathering of information pertinent to (not necessarily exactly the information the other party desires to have) the communication

parties. Functions that are classified in the interpretation level have the following characteristics:

- Information for communicating to the other end may come from several sources. Searching of related information is necessary.

- Content data are consolidated, re-arranged. Meanings of data are extracted.

- Merging and de-merging of data are typical activities required at this level. However, the format of data remains unchanged, for example, text data remains as text data.

Web communication via a portal and server side capabilities can be classified at this level.

\section{Presentation level}

The presentation level is the interface between application level and interpretation level. It contains the functions to convert the information to a format suitable to be used by the application that the toolmaker wants to run. For example, a toolmaker may receive a facsimiled drawing. A system is required to convert this information into a computer model. There is no fundamental change of the content of the information. Communication between two communicating parties at this level requires evaluation and perhaps, confirmation of the accuracy in the content of information being transmitted. Functions that are classified in the presentation level have the following characteristics:

- Data for communication is transformed into a different format as required by the applications.

- Each application will produce data from its own data sources. Some synchronisation of data may be required.

- The content of communication can be changed to produce a coherent presentation for the receiving party.

Internet document services provided by team collaboration tools such as TeamSpace and Quickplace can be classified at this level.

\section{Application level}

The application level describes the functions that a toolmaker needs to use for processing the information in their work. For example, the toolmaker may use the information as a basis to design a new tool, or he/she will use the information to schedule the machines for the next 24 hours. Two toolmakers, or the customer and the toolmaker must communicate at this level in order that the VE can fulfil its mission. Functions that are classified in the application level have the following characteristics: 
- Information for communication is created, changed, processed, and extracted as required by the applications. There is no restriction in the size, format, form and nature of data generated in this level.

- Applications will own their own data sources. Sharing of data across applications is possible. Sharing of data across the company is not allowed.

- For sharing data across the company boundary, the information needs to be transmitted through RCF.

This level of ICT capability involves sophisticated web work platforms such as Microsoft Project Server, ProjectLink, MatrixOne and other interoperable application software.

\section{Case Studies}

Five VEs are studied to explore how supply chain sustainability are reflected in their operations while they progress through various stages of VERA. The aim is to detect the complete end-to-end activities in a process map which can then be analysed to identify issues affecting interoperability in the VEs.

\section{Case Study 1: AGILENET}

It is observed that in many industries, clients are seeking shorter runs of bundled products and services. Potentially, small firms have the ability to provide such flexibility, but on occasions may need to pool their resources to access sufficient breadth of capability or capacity. The AGILENET Collaboration of Tier 2 and Tier 3 suppliers draw on these strengths and pool resources in a dynamically changeable way (Beckett, 2004).

The AGILENET started with a series of informal discussions (meetings) among several toolmakers in various meeting venues. In the conceptual phase, no written information existed. Phone calls and ad hoc invitation notes were common communication technologies used in this environment. As the network became more mature, individual companies began to contact each other and cross-visited their factories to ascertain the basis of collaboration. A couple of companies were keen to move forward and proposed some ideas of how the AGILENET should be organised. A draft agreement of collaboration was circulated stating the intention for a range of activities:

- Inter-firm trading in support of individual participant firm projects

- Joint internal projects such as the exploration of joint purchasing possibilities

- Sharing market intelligence

- Collaborative R\&D

Hence, AGILENET only requires to use Basic Level communication technologies.

\section{Case Study 2: Collaboration Among 3 Tool Makers}

The second VE studied was a collaborative consortium involving 3 toolmakers. Due to commercial reasons, we keep the toolmakers anonymous and use names $A, B$ and $C$ instead. One of the toolmakers $(A)$ received a customer order. The tool was a bit more complicated and he required skills from two other toolmakers (B and $C$ ) to complete the task. In the project, Toolmaker A was the prime contact with the customer and responsible for the delivery of the product (the tool).

At the conceptual phase of the project, Toolmaker A received part information from the customer. As most of this information was high level part requirements and design models, 
he arranged meetings with $B$ and $C$ to discuss how the tool should be put together. At this stage, meetings and discussions were generally arranged via phone and facsimile, while contracts and related documentations were handled by emails.

When the team entered into design phases, the situation was more complicated when they exchanged design information. Toolmaker A used a professional CAD system. Toolmaker $B$ used a simple drafting software. Toolmaker $C$ was a small tool shop and did not have a CAD system.

At the start of the tool design, Toolmaker A developed an overall view of the tool in his CAD system. In order to transfer the information to the other toolmakers, Toolmaker A extracted the tool model into a STEP file. The STEP file was passed to Toolmaker $B$ on a CD. Toolmaker A also plotted the drawings for Toolmaker C. In addition, Toolmaker A compiled supplementary product information that the other toolmakers needed to design the tool. At the receiving end, Toolmaker $B$ received the STEP model and relevant information. The geometrical data were captured in his drafting software. Most of the data were accepted except some critical sections which Toolmaker B had to compare with the drawings supplied and made necessary corrections. Toolmaker B then took this model together with other product information and developed a specification to manufacture the product. A couple of experienced engineers were involved in this process.

On the other hand, Toolmaker $\mathrm{C}$ used the drawings and the supplementary information from Toolmaker A. Some errors of interpretation were encountered but with more frequent meetings and reviews, the job was finally done.

A process map of the above activities was recorded in Figure 3.

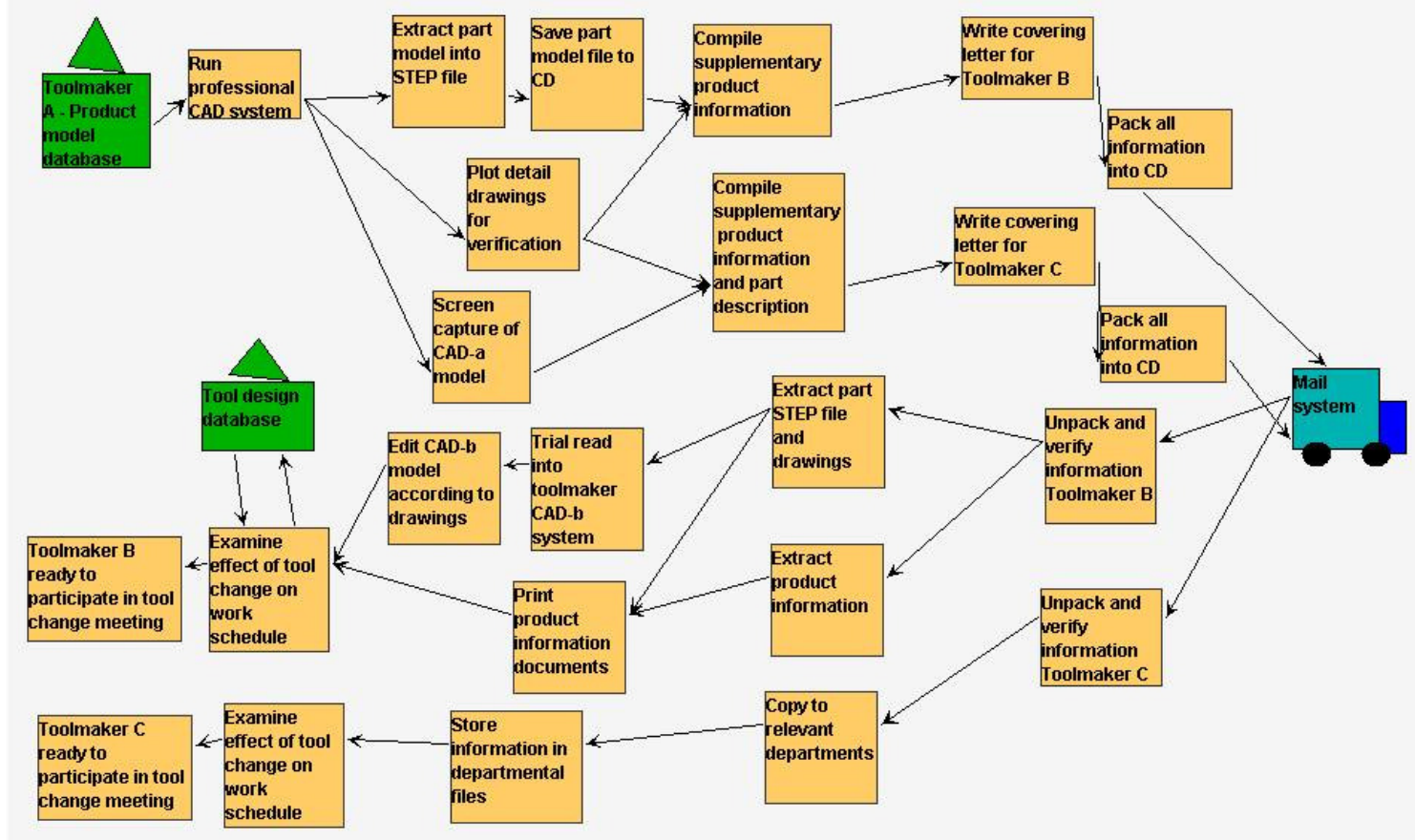

Figure 3 - Collaborative tool design project among 3 toolmakers

During the project, Toolmaker $\mathrm{B}$ and $\mathrm{C}$ were requested to upgrade their communication capabilities to match that of Toolmaker A. However, the cost of upgrading to new CAD systems not only involved the cost of software, but also included training and other maintenance costs. There were some contention in the process and a compromise by 
Toolmaker A was made. Nevertheless, most communications were done in batch mode through emails and document exchanges, which means the collaborative toolmakers were at the basic and verification levels.

\section{Case Study 3: Aerospace Tooling VE}

The Aerospace Tooling VE was a much larger project involving over 30 toolmakers of wide variety of skills. The VE was organised in a 2 tier structure with 3 master toolmakers responsible for liaison with the customer (Mo et al, 2005). When the VE was studied, the Aerospace Tooling VE was already working on producing the tool for the customer. Scheduling tool components delivery to the master toolmakers was an essential collaborative task for all companies in the VE.

The scale of the project also brought some advantage in communication profiling. All toolmakers in the VE had been using CAD systems from various vendors. Transfer of design information had occurred and the partners managed to resolve the discrepancies between CAD models held by difference companies. The VE also agreed to exchange scheduling information via a standard format, that is, Excel spreadsheet.

The actual coordination within the VE was a bit more complicated. A few toolmakers were actually using MS Project as the scheduling and planning tool. Figure 4 shows a block diagram of the scheduling and costing system used by the lead company in the VE.

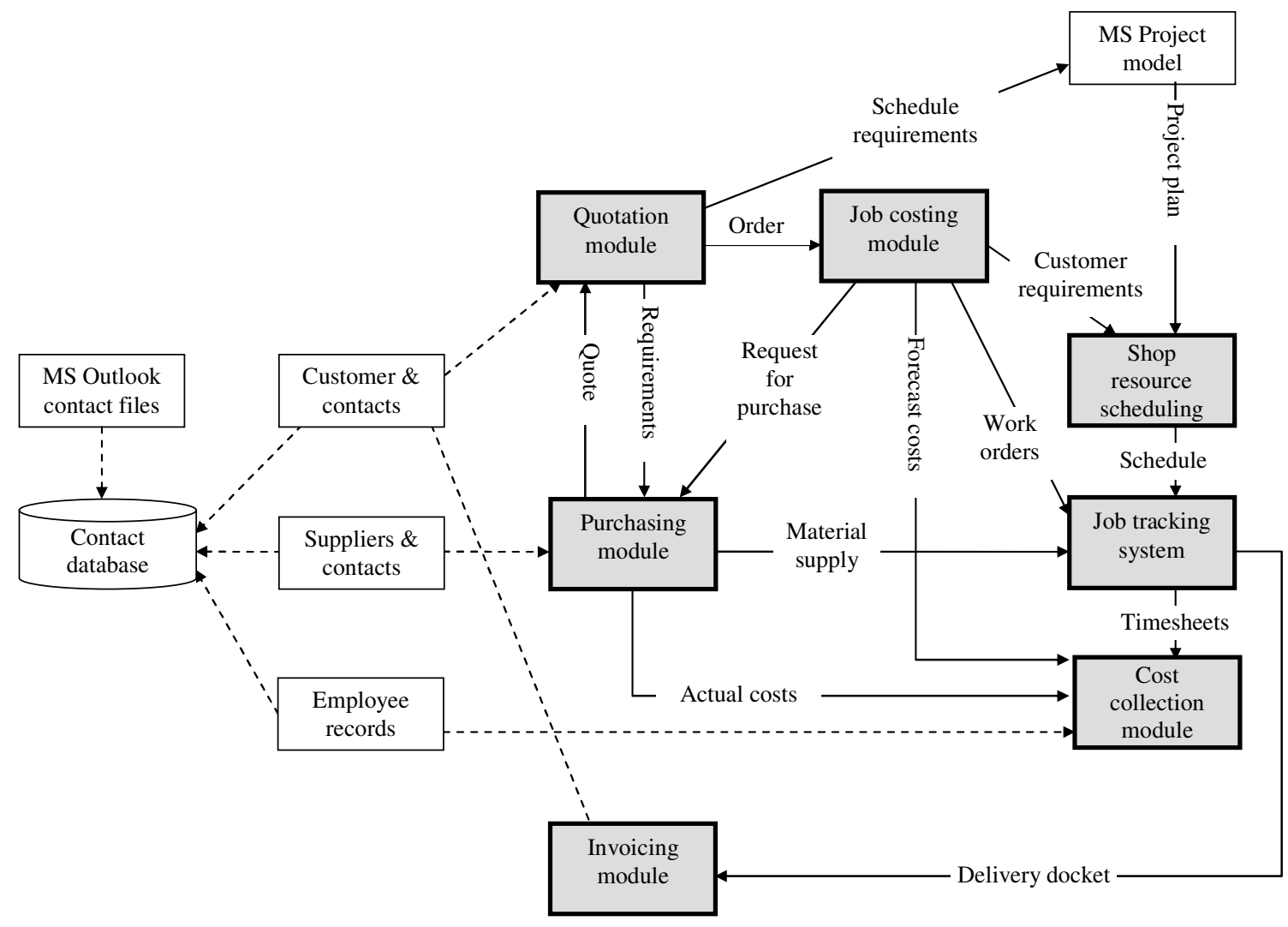

Figure 4 Scheduling and costing system

In order to enable transfer of information from this system to other partners in the VE, a data portal that allows massive data upload and download was maintained. Most project control data transfer are exported MS Project format. In addition, supplementary documentation of 
project control was added to Excel file manually. Since the design was basically confirmed (minor adjustments were still required but these were limited by consensus within the VE), and the synchronisation of production schedule was only required once a week, the consortium found that the extra manual work in the process was manageable.

As the product was close to completion, most of the tool components were delivered to the master toolmakers and the communication requirements diminished. Changes and error corrections were generally handled by meetings and phone discussions. The more sophisticated engineering data exchanges as well as document management demanded (from basic) up to presentation level.

\section{Case Study 4: Maintenance Enterprise}

Over the life time of the asset (30 years), changes due to new technologies, people and defence requirements are inevitable. The service system developed to support continuous improvement of the capability of the asset was the ANZAC Ship Alliance (ASA). Initially, Hall (2000) developed a highly integrated documentation and configuration management system that served the on-going need of ten ANZAC class frigates. The ASA implemented upgrades on the ships which were actually in service.

The ANZAC Ship Alliance (ASA) can be thought of as a virtual company with shareholders comprising the (Australian) Commonwealth, Tenix Defence, and Saab Systems. The mission of the ASA is to manage all change and upgrades to the ANZAC Ships. The ASA is a "solution focused" company where the staff of the ANZAC Ship Alliance Management Office will develop change solutions but the detailed design be undertaken by the "shareholders" drawing upon their existing and substantial knowledge of the ANZAC Class (Mo et al, 2006). The Business Model of ASA has the following features:

- All parties win or all parties lose

- Collective responsibility, equitable sharing of risk and reward

- All decisions based on "best for project" philosophy

- Access to resources, skills and expertise of all parties

- All financial transactions are fully open book

- Encouragement of innovative thinking - outstanding outcomes

The VE operated as a series of nested VERA lifecycles as shown in Figure 5. 


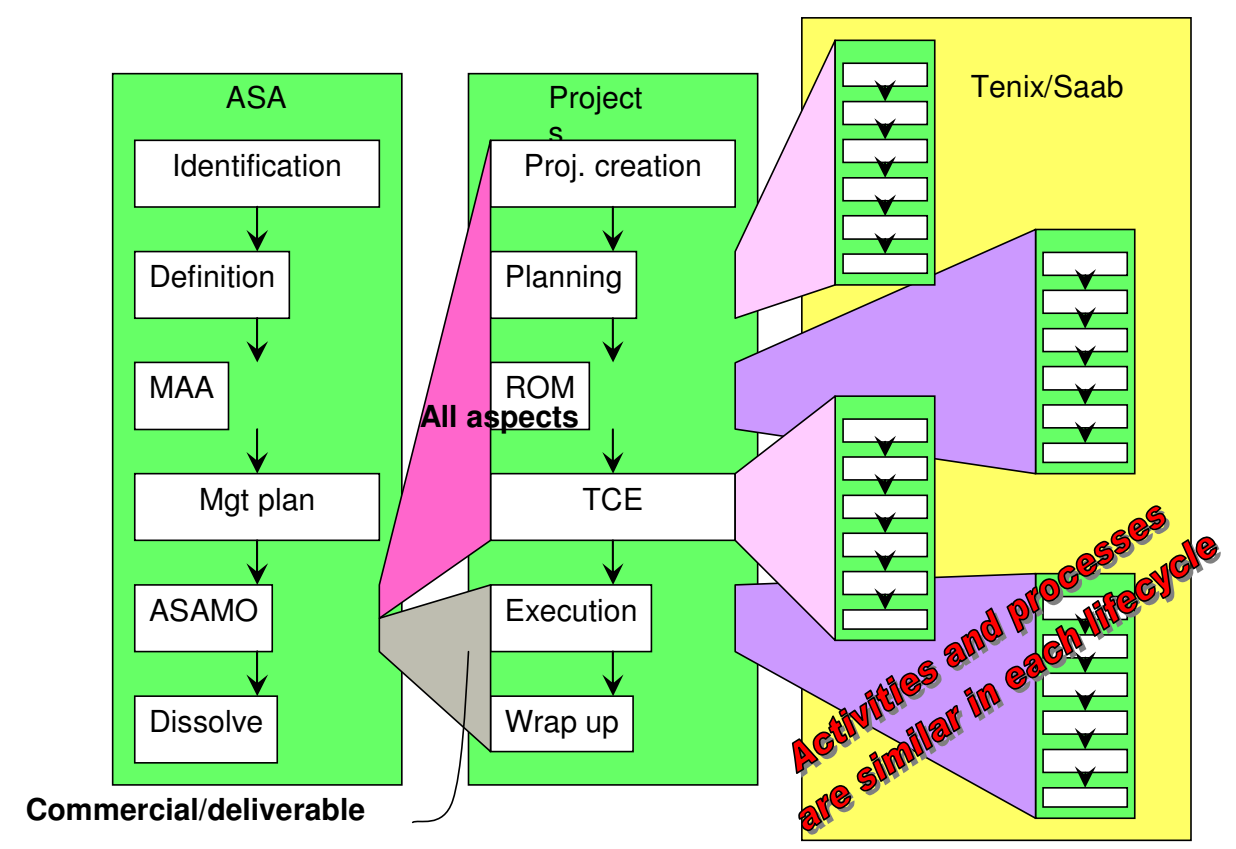

Figure 5: Nested life cycle of ASA VE

Due to the large number of staff from various companies involved, changes on the portal become difficult to be followed. The ASA investigated the use of collaborative tools that have the ability to keep track of changes and notifying appropriate managers as required. A number of collaborative tools including WelcomeHome and Windchill were evaluated against the VE's requirements. It is clear from this case study that the ASA was operating at all levels of the VCF.

\section{Case Study 5: Multi-national servicing virtual enterprise}

In managing the design and manufacture of a chemical plant for their customer, Kamio et al (2002) established a service virtual enterprise (SVE) with several partner companies around the world providing after-sales services to a customer (Figure 6). Each partner was an independent entity that was equipped with its own unique capabilities and competencies, assuming responsibility to perform the allocated work. The SVE was designed as a "hosting service" which had a broad range of services including plant monitoring, preventive maintenance, trouble-shooting, performance simulation and evaluation, operator training, knowledge management and risk assessment. Participants of the virtual enterprise had welldefined roles and responsibilities. 


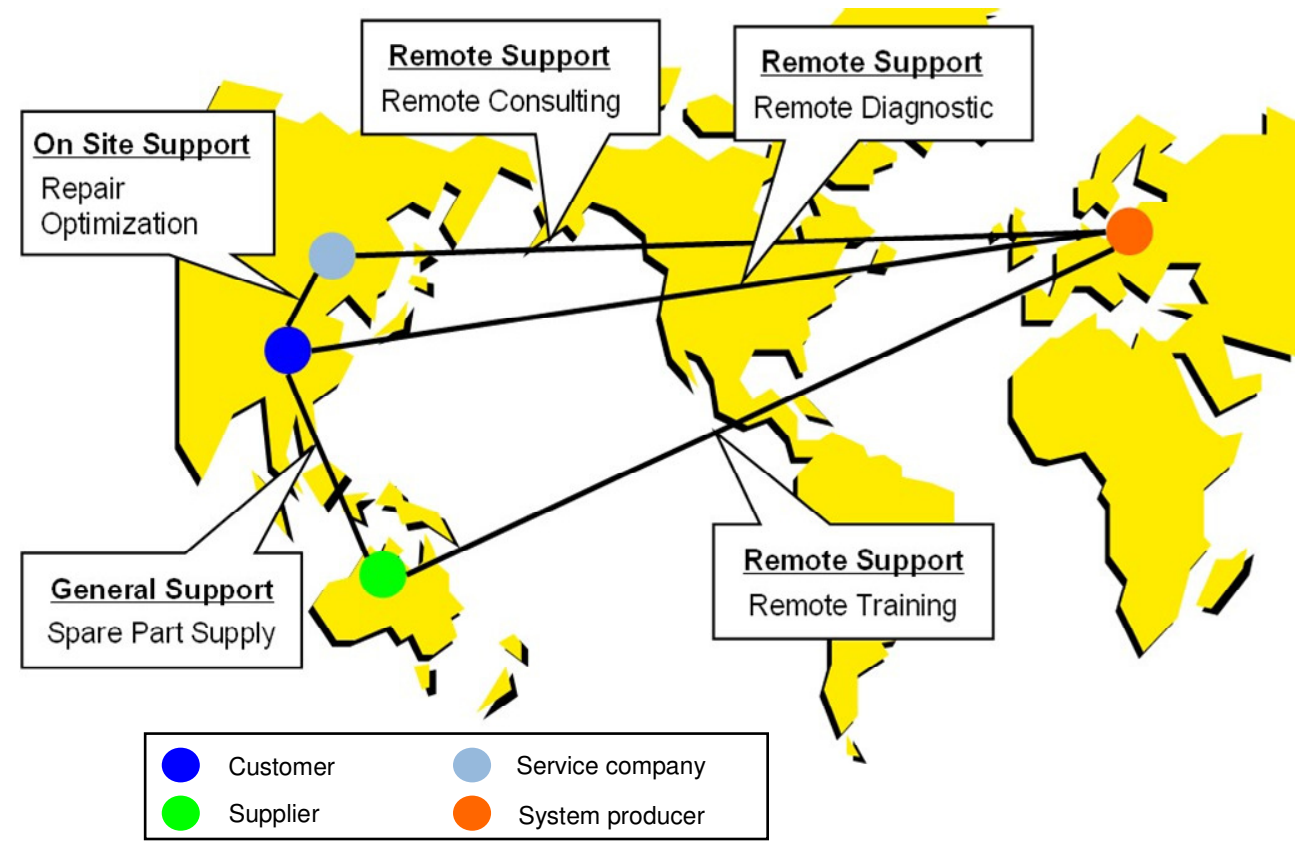

Figure 6: A globally distributed service virtual enterprise

The operation of SVE is clear and defined. The leading company in the SVE took the responsibility to develop a fully functional service internet presence which has the ability to provide chat, data search, enquiry, project tracking and other project related capabilities. Again this case study shows clearly that all supply chain partners operated at all VCF levels.

\section{General Observations}

Hence, it is proposed that a five level communication technology scheme can be formulated according to the life cycle phases as shown in Table 1.

\begin{tabular}{|l|c|c|c|c|c|}
\cline { 2 - 6 } \multicolumn{1}{c|}{} & \multicolumn{5}{c|}{ VCF Technology Levels } \\
\cline { 2 - 6 } \multicolumn{1}{c|}{} & Basic & Verification & Interpretation & Presentation & Application \\
\hline $\begin{array}{c}\text { Life cycle } \\
\text { phase }\end{array}$ & e.g. Phone & e.g. Email & e.g. Portal & $\begin{array}{c}\text { e.g. } \\
\text { Computer } \\
\text { support } \\
\text { collaborative } \\
\text { tools }\end{array}$ & $\begin{array}{c}\text { e.g. } \\
\text { Integrated } \\
\text { service } \\
\text { tools }\end{array}$ \\
\hline $\begin{array}{l}\text { Concept and } \\
\text { Requirements }\end{array}$ & $\sqrt{ }$ & & & & \\
\hline Prelim. design & $\sqrt{ }$ & $\sqrt{ }$ & $\sqrt{ }$ & \\
\hline $\begin{array}{l}\text { Detailed } \\
\text { design }\end{array}$ & $\sqrt{ }$ & $\sqrt{ }$ & $\sqrt{ }$ & \\
\hline Implementation & $\sqrt{ }$ & $\sqrt{ }$ & $\sqrt{ }$ & \\
\hline Operation & $\sqrt{ }$ & $\sqrt{ }$ & & & \\
\hline
\end{tabular}

Table 1 - Use of key communication technologies at different life cycle phase of VE 
The observation of the case studies reveals an important fact of life. For a virtual enterprise to sustain its operation:

- All partners in the virtual enterprise, irrespective of its size, must communicate with an agreed protocol;

- A unified (or standard) information and physical architecture must be agreed upon by all partners in the virtual enterprise;

- Irrespective of the level of ICT employed by individual toolmakers, the lower level functions must be fulfilled by alternative technologies;

- The information and physical architectures must be in place in all entities (Network, Project and Product) and in all phases of the virtual entities. The architectures will vary in content.

The VCF provides a reference to communication technology level is required for carrying out activities in the VE effectively. It is necessary to point out that the functional modules can either be software, hardware or a combination of both. All levels (except the basic connection) can be implemented in software and equally, all levels can be implemented in hardware. Hardware modules tend to be used for lower level applications. However, as In a virtual enterprise environment involving human participants, the situation is more complicated. The level of communication technology can vary greatly between companies. The technology level affects the effectiveness of communication between two parties. Large corporations complain that their smaller partners in the virtual enterprise are reluctant to keep up with their IT policies and systems. Small companies do not have adequate resources to support a full team (in many cases, a full time) IT staff in the organisation. The communication capability is often managed in an ad hoc fashion.

Using VCF, the change in communication requirement can be illustrated as a function of against the life cycle phases in VERA (Figure 7).

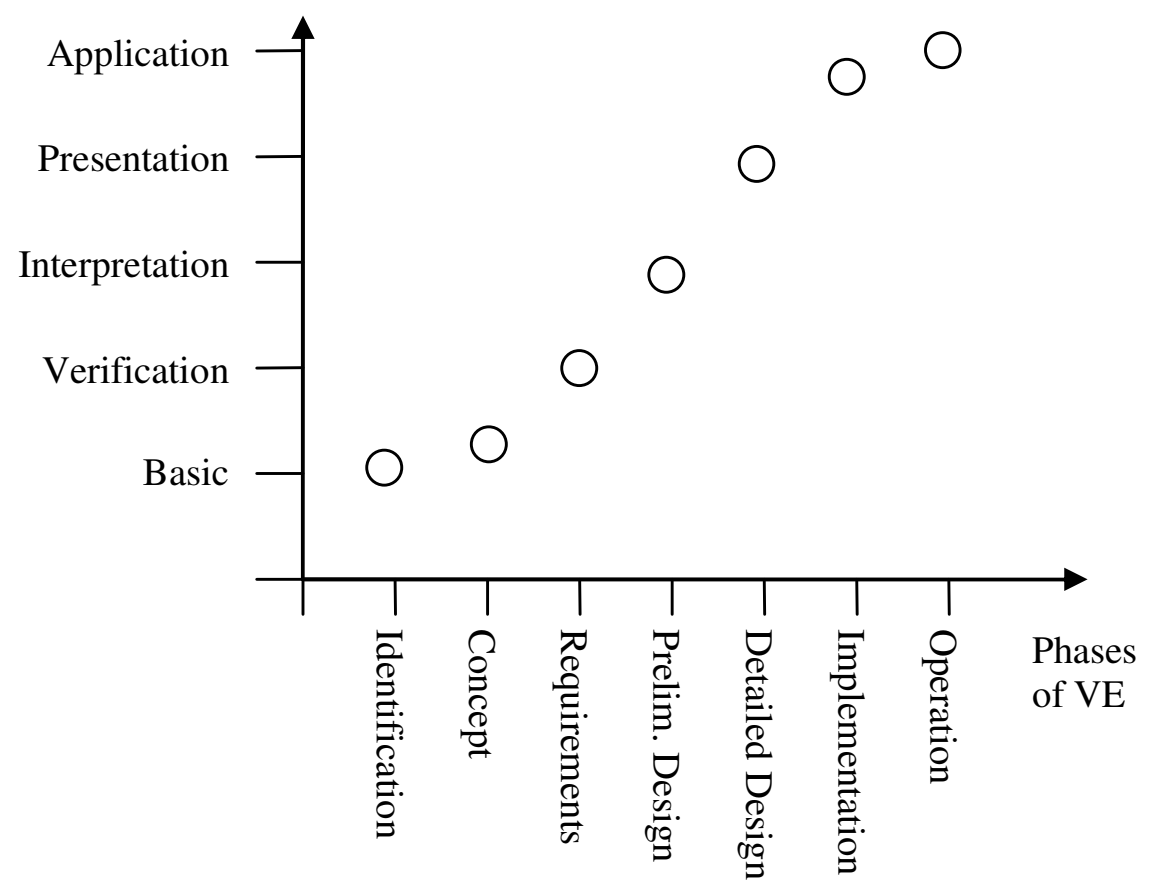

Figure 7 Communication profile in VERA 


\section{Conclusion}

The characteristics of collaborative engineering supply chains known as virtual enterprises are the need to communicate and agree on an aligned action towards a common goal. In this paper, we applied the case study research method to investigate the governing system design parameters that govern the risks of SMEs investing into ICT in order to join the virtual enterprise and operate effectively within.

Based on the case study research methodology, it is proposed that if the SMEs have the tools and hence the ability to assess their own ICT level, and the ability to foresee the level of technology requirements in the virtual enterprise that they want to join, the risk of SMEs spending the investment while still failing the adaptation in the communication system of the virtual enterprise can be significantly reduced. According to the virtual enterprise reference architecture, a five level ICT technology framework is proposed in this paper.

As the virtual enterprise advances through the virtual enterprise reference architecture life cycle, the complexity of information to be communicated increases as the project progresses. For example, case 1 shows that use of web-based reporting is not a good strategy at the start of the project due to the information normally being unstructured. People do not have a confirmed interpretation format. If nothing gets on the web, it becomes boring and people lose interest. At the later stage of the virtual enterprise life cycle, the complexity requires that some agreed format of the information is required as shown in case 4 and case 5 . The essential bits of data are defined so that people find the information useful. The complexity of data requires certain level of ability of the communication framework, which implies a higher level within VCF. Hence, the communication technology profiles can be conveniently specified within a virtual enterprise and individual partners will be able to use VCF as a guideline to determine what ICT investments are required against the status of the virtual enterprise.

The partners participate because there are business objectives to be fulfilled by operations within their companies and collaborating with other companies within the virtual enterprise. Application of different levels of communication technology will enhance the effectiveness of the VE but does not necessarily increase its capability. However, appropriate technology used in the communication systems will provide certainty in satisfying the objectives of the VE.

Using the five level model, the five cases in engineering services supply chains were studied and the technologies in these cases were mapped against the ICT levels in the framework. VCF promotes the understanding and mapping of how communication technology capabilities in an engineering services VE. It was found that there is strong relationship between the life cycle phases of the virtual enterprise as compared to the virtual enterprise communication framework. The case studies show that the VCF is a generic framework for ICT capability assessment.

\section{Reference}

Abe, T. (2005). What is Service Science. Research Report, No.246, December. The Fujitsu Research Institute, Economic Research Centre, Tokyo, Japan

Barradas L.C.S., Pinto-Ferreira J.J., (2004). P2P Infrastructure for tourism electronic marketplace. $18^{\text {th }}$ IFIP World Computer Congress, 22-27 August, Toulouse, France, Paper 49 
Beaumont, N.B. (1998). Investment decisions in Australian manufacturing. Technovation. 18(11), 689-695

Beckett, R.C. (2003). Determining the anatomy of business systems for a virtual enterprise, Computers in Industry, 51, 127-138

Beckett, R.C. (2004). Exploring sustainable virtual enterprises - two case studies. In Virtual Enterprises and Collaborative Networks, Eds. Camarinba-Matos, L.M., pub. Kluwer, ISBN 1-4020-8138-3, pp.491-498

Bhaskaran, S., Gligorovska, E. (2009). Information communication technology adoption by small-to-medium-sized food enterprises in Australia, International Journal of Enterprise Network Management. 3(4), 332-346

Bielli, M., Bielli, A. (2008). Innovation paths management in collaborative enterprise clusters. International Journal of Enterprise Network Management. 2(4), 366-376

Brammer, S., Walker, H. (2011). Sustainable procurement in the public sector: an international comparative study. International Journal of Operations \& Production Management, 31(4), 452-476

Braziotis, C.; Tannock, J. (2007)., "Review of Strategic Alignment Process and Decision Support Systems - Theory and Case Studies", Journal of Manufacturing Technology Management, Vol.18 (2).

Canavesio, M.M., Martinez, E. (2007). Enterprise modeling of a project-oriented fractal company for SMEs networking. Computers in Industry. 58(8/9), 794-813

Chatha, K A, Ajaefobi, J.O., Weston, R.H. (2006). Enriched multi-process modelling in support of the life cycle engineering of Business Processes. International Journal of Production Research. DOI: 10.1080/00207540600607150

Chattopadhyay S., Mo, J.P.T. (2010). "Modelling a global EPCM (Engineering, Procurement and Construction Management) Enterprise", International Journal of Engineering Business Management, Vol.2, No.1, pp.1-8

Cheng K., Popov Y. (2004), Internet-enabled modelling of extended manufacturing enterprises using process-based techniques, International Journal of Advanced Manufacturing Technology, 23, 148-153

Chiu, R.K., Tsai, K.C., Chang, C.M., Koh, S.C.L., Lin, K.C. (2007). The implementation of an agile information delivery system in building service-oriented e-healthcare Network. International Journal of Enterprise Network Management, 1(3), 283 - 298

COSBOA (Council of Small Business of Australia) (2010). Small Business in Australia. http://www.cosboa.org/webs/cosboa/cosboa.nsf/vwAll/Small\%20Business\%20in\%20Au stralia, retrieved 10 April, 2011

Costa C.A., Harding J.A., Young, R.I.M. (2001). The application of UML and an open distributed process framework to information system design, Computers in Industry, 46, 33-48

Dewhurst, F.W., Barber, K.D., Pritchard, M.C. (2002). In search of a general enterprise model. Management Decision, 40(5), 418-427

Dilts D.M., Boyd N.P., Whorms H.H. (1991). The evolution of control architectures for automated manufacturing systems, Journal of Manufacturing Systems, 10, 1, 79-93

Ekanem, I. (2005). Bootstrapping: the investment decision-making process in small firms. The British Accounting Review,.37, 299-318

Espinosa, A., Porter, T. (2011). Sustainability, complexity and learning: insights from complex systems approaches. The Learning Organization, 18(1), 54-72

Grünbaum, N.N. (2007). Identification of ambiguity in the case study research typology: what is a unit of analysis? Qualitative Market Research: An International Journal, 10(1), 78-97

Hall W.P., (2000). "Managing Technical Documentation for Large Defence Projects: Engineering Corporate Knowledge", Global Engineering, Manufacturing and Enterprise Networks, 15-17 November, Melbourne, Australia, pp.370-378

Hansen, A. (2011). Relating performative and ostensive management accounting research: Reflections on case study methodology, Qualitative Research in Accounting \& Management. 8(2), 108-138 
Hao Q., Shen W., Wang L., (2005). Towards a cooperative distributed manufacturing management framework, Computers in Industry, 56, 71-84

Holschbach, E., Hofmann, E. (2011). Exploring quality management for business services from a buyer's perspective using multiple case study evidence, International Journal of Operations \& Production Management, 31(6), 648-685

Hossam A. Gabbar, Yukiyasu Shimada, Kazuhiko Suzuki, (2002). Computer-aided plant enterprise modeling environment (CAPE-ModE) - design initiatives, Computers in Industry, 47, 25-37

Huang, L.K. (2008). Top management support and IT adoption in the Taiwanese small and medium enterprises: a strategic view. International Journal of Enterprise Network Management, 2(3), 227-247

IfM, IBM (2008). Succeeding through Service Innovation: A service perspective for education, research, business and government, A White Paper based on Cambridge Service Science, Management and Engineering Symposium (July 2007) and The consultation process (October - December 2007). ISBN: 978-1-902546-65-0, pub. University of Cambridge, UK, 33 pages

ISO, (1983). Open Systems Interconnection - Basic Reference Model, ISO 7498

Jiang H.C., Mo J.P.T., (2001). Internet Based Design System for Globally Distributed Concurrent Engineering, Journal of Cybernetics and Systems, 32(7), 737-754

Johansson, P., Olhager, J. (2006). Linking product-process matrices for manufacturing and industrial service operations, International Journal of Production Economics, 104(2), 615-624

Kamio, Y., Kasai, F., Kimura, T., Fukuda, Y., Hartel, I., Zhou, M. (2002) Providing Remote Plant Maintenance Support through a Service Virtual Enterprise. VTT Symposium 224, Global Engineering and Manufacturing in Enterprise Networks, 9-10 December, Helsinki, Finland, pp.195-206

Kucza, G., Gebauer, H. (2011). Global approaches to the service business in manufacturing companies. Journal of Business \& Industrial Marketing, 26(7), 472-483

Lewis, A., Elmualim, A., Riley, D. (2011). Linking energy and maintenance management for sustainability through three American case studies. Facilities. 29(5/6), 243-254

Lockett, H., Johnson, M., Evans, S., Bastl, M. (2011) Product Service Systems and supply network relationships: an exploratory case study. Journal of Manufacturing Technology Management, 22(3), 293-313

Malladi, S., Min, K.J., (2005). Decision support models for the selection of internet access technologies in rural communities, Telematics and Informatics, 22, 201-219

Mills J., Brand M., Elmarsi R., (1998). "AeroWEB: An Information Infrastructure for the Supply Chain", IFIP TC5 WG5.3/5.7 Third International Conference on the Design of Information Infrastructure Systems for Manufacturing (DIISM '98), May 18-20, Fort Worth, Texas, U.S.A., 323-336

Mo J.P.T., Beckett R., Nemes L., (2005). Technology Infrastructure for Virtual Organisation of Tooling, Sixth IFIP Working Conference on Virtual Enterprises (PRO-VE'05), 26-28 September, Valencia, Spain

Mo J.P.T., Menzel C. (1998). "An integrated process model driven knowledge based system for remote customer support", Computers in Industry, 37, 171-183

Mo J.P.T., Zhou M., Anticev J., Nemes L., Jones M., Hall W., (2006). "A study on the logistics and performance of a real 'virtual enterprise'", International Journal of Business Performance Management, 8(2/3), 152-169

Mo, J.P.T., Woodman, S., O'Brien, S. (2001). Analysis of Current Production Practices Production Efficiency Improvement Program of the Furniture Industry Association of Australia. CSIRO public report, May, 103 pages

Nemes L., Mo J.P.T., (2004). Collaborative Networks in Australia - Challenges and Recommendations, in Collaborative Networked Organizations, ed. Camarinha-Matos L.M., Afsarmanesh H., pub. Kluwer Academic Publishers, ISBN 1-4020-7823-4, 97102 
Nosek J.T., (2005). Collaborative Sensemaking Support: Progressing from Portals and Tools to Collaboration Envelopes, International Journal of e-Collaboration, 1(2), 25-39

Perry, C. (1998). Processes of a case study methodology for postgraduate research in marketing. European Journal of Marketing, 32(9/10), 785-802,

Pinsonneault A., Caya O., (2005). Virtual Teams: What We Know, What We Don't Know, International Journal of e-Collaboration, 1(3), 1-16

Scapens, R.W. (2011). The Case Study as Research Method: A Practical Handbook, Qualitative Research in Accounting \& Management, 8(2), 201-204

Serra, F.R., Ferreira, M.P. (2010). Emerging determinants of firm performance: A case study research examining the strategy pillars from a resource-based view. Management Research: The Journal of the Iberoamerican Academy of Management. $8(1)$, pp. 7-24

Seuring, S.A. (2008). Assessing the rigor of case study research in supply chain management. Supply Chain Management: An International Journal, 13(2), 128-137

Sharma, M.K. (2007). Information system architecture: a framework for Indian small and medium enterprises. International Journal of Enterprise Network Management, 1(4), 406-424

Shen, H., Wall, B., Zaremba, M., Chen, Y., Browne, J., (2004). Integration of business modelling methods for enterprise information system analysis and user requirements gathering, Computers in Industry, 54, 307-323

Shen, Z.J.M., Daskin, M.S. (2005). Trade-offs Between Customer Service and Cost in Integrated Supply Chain Design, Manufacturing and Service Operations Management, 7(3), 188-207

Shinonome M., Nemes L., Zhou M., Mo J., Bernus P., Uppington G., (1997). Project Enterprise, Proceedings of IMS Research Results Presentation, 10-11 September, Tokyo, Japan, Paper No. IMS9607, sponsored by Manufacturing Science and Technology Centre, Japan

Spohrer, J., Maglio, P.P., Bailey, J., Gruhl, D. (2007). Steps Toward a Science of Service Systems, Computer, Jan, 40(1), 71-77

Van den Berg R.J., Tolle M., (2000). Assessing Ability to Execute in Virtual Enterprises, in Global Engineering, Manufacturing and Enterprise Networks, ed. Mo J.P.T., Nemes L., IFIP TC5 WG5.3/5.7/5.12 Fourth International Working Conference on the Design of Information Infrastructure Systems for Manufacturing (DIISM 2000), November 15-17, Melbourne, Australia, 38-45

Van Donk, D.P., van der Vaart, T., Zhang, X. (2011). Does ICT influence supply chain managmenet and performance? A review of survey-based research, International Journal of Operations \& Production Management, 31(11), current issue

Williams T.J., (1994). The Purdue Enterprise Reference Architecture, Computers in Industry, 24(2/3), 141-158

Yin, R.K. (2009). Case Study Research: Design and Methods, 4/e, SAGE Publications, ISBN: 9781412960991

Yin, R.K. (2004). The Case Study Anthology, SAGE Publications, ISBN: 9780761929253

Yu, B., Harding J.A., Popplewell K. (2000). A reusable enterprise model. International Journal of Operations \& Production Management. 20(1), pp.50-69

Yun, G.C., Shin D.Y., Kim, H.S., Lee, S.Y. (2010). Knowledge-mapping model for construction project organizations, Journal of Knowledge Management, 15(3), 528-548

Zarour N., Boufaida M., Seinturier L., Estraillier P., (2005). Supporting virtual enterprise systems using agent coordination. Knowledge and Information Systems, 8, 330-349, Springer-Verlag

Zwegers A., Tolle M., Vesterager J., (2003). VERAM: Virtual Enterprise Reference Architecture and Methodology, in Global Engineering and Manufacturing in Enterprise Networks, ed. Karvonen I., van den Berg R., Bernus P., Fukuda Y., Hannus M., Hartel I., Vesterager J., VTT Symposium 224, Helsinki, Finland, 9-10 December, 17-38 